\title{
Hubungan Stimulasi Orang Tua Terhadap Perkembangan Bicara dan Bahasa Anak Usia Batita
}

\author{
Fenny Fernando ${ }^{1}$, Etriyanti $^{2}$, Melia Pebrina ${ }^{3}$ \\ ${ }^{1,2,3}$ STIKES Syedza Saintika Padang \\ Jl. Prof. Dr. Hamka No. 228 Air Tawar Timur Kecamatan Padang Utara, 25132 \\ ${ }^{1}$ Fennyfernando87@gmail.com, ${ }^{2} y a t i e t r i 84 @ y a h o o . c o . i d,{ }^{3}$ meliapebrina88@gmail.com
}

\begin{abstract}
Abstrak
Perkembangan bicara dan bahasa anak yang optimal tidak lepas dari cara orang tua dalam menstimulus anaknya.. Anak yang memperoleh stimulus yang terarahkan lebih cepat berkembang dibandingkan anak yang kurang memperoleh stimulus dan apa bila orang tua mematikan inisiatif anak, maka hal tersebut akan membuat anak bersalah. Tujuan penelitian diketahuinya hubungan stimulasi orang tua dengan perkembangan bicara dan bahasa anak usia batita di Wilayah Kerja Puskesmas Tanah Garam Kota Solok tahun 2018. Penelitian ini menggunakan desain Deskriptif Analitik dengan rancangan Cross Sectional. Populasi penelitian adalah seluruh orang tua yang memiliki anak batita jumlah 109 di Wilayah Kerja Puskesmas Tanah Garam Kota Solok, dengan sampel orang tua dan balita sebanyak 86 orang. Analisa hasil dilakukan dengan menggunakan Uji Chi-square. Hasil penelitian ini didapat data bahwa anak balita yang mengalami suspek dalam perkembangan bicara dan bahasa sebanyak 42\%, dan 58\% orang tua kurang optimal melakukan stimulasi kepada anak batita. Hasil analisis statistik chi square diperoleh $p=0,000$ $(p<0,05)$, terdapat hubungan antara stimulasi terhadap perkembangan bicara dan bahasa anak batita di Wilayah Kerja Puskesmas Tanah Garam Kota Solok tahun 2018. Dapat disimpulkan bahwa pemberian stimulasi akan mengoptimalkan perkembangan bicara dan Bahasa anak batita. Disarankan kepada orang tua agar selalu memberikan sentuhan saat berbicara dengan anak.
\end{abstract}

Kata kunci: Stimulasi, Perkembangan bicara, Bahasa.

\section{The Relationship of Parents 'Stimulation on The Development of Talk And Language Children Age}

\begin{abstract}
The optimal development of speech and language of children is inseparable from the way parents stimulate their children. Children who get directed stimuli develop faster than children who do not get the stimulus, and what if parents turn off the initiative of the child, then this will make the child guilty. The research objective was to know the relationship of stimulation of parents with the development of speech and language of toddlers in the Work Area of the Tanah Garam Public Health Center in Solok in 2018. This study used a descriptive-analytical design with a cross-sectional design. The population in this study were all parents who have toddlers numbering 109 in the Tanah Garam Community Health Center Working Area in Solok City, with a sample of parents and toddlers as many as 86 people. The results of the analysis were carried out using the Chi-square test. The results of this study obtained data that children under five who experience suspicion in speech and language development as much as $42 \%$, and $58 \%$ of parents are less optimal in stimulating toddlers. From the results of chisquare statistical analysis obtained $p=0,000(p<0.05)$, this shows there is a relationship between stimulation of speech and language development of toddlers in the Work Area of the Solok City Garam Health Center in 2018. The results of this study concluded that stimulation would optimize the development of toddlers' speech and language. It has recommended that parents always give touch when talking to children.
\end{abstract}

Keywords: Stimulation, Speech development, Language. 


\section{PENDAHULUAN}

Periode penting dalam tumbuh kembang anak adalah masa balita . karena pada masa ini perkembangan kemampuan berbahasa,kreativitas, kesadaran social, emosional, moral, dasar-dasar kepribadian, dan intelegensi berjalan sangat cepat dan merupakan landasan perkembangan berikutnya. Bahkan ada sajana yang mengatakan bahwa "the child is the father of the man". sehingga setiap kelainan atau penyimpangan sekecil apapun apabila tidak terdeteksi dan tidak tertangani dengan baik dapat mengurangi kualitas sumber daya manusia dikemudian hari. Oleh sebab itu diperlukan rangsangan atau stimulasi yang berguna agar potensi dapat berkembang baik (Soetjiningsih, 2013).

Gangguan pada perkembangan bicara merupakan keadaan dimana seseorang tidak dapat menggunakan simbol linguistik untuk berkomunikasi secara verbal atau terjadi keterlambatan dalam perkembangan bicara. Seorang anak dikategorikan mengalami gangguan perkembangan bicara apabila terjadi keterlambatan perkembangan bicara sesuai kelompok umur, jenis kelamin, adat istiadat dan kecerdasan anak (Hartanto. Selina, Zubrial \& Fitra, 2011).

Pada saaat ini berbagai metode deteksi dini untuk mengetahui gangguan perkembangan anak telah dibuat. Menilai perkembangan anak dapat dilakuakan pertama kali adalah melakukan wawancara tentang faktor kemungkinan yang menyebabkan gangguan dalam perkembangan, tes skrining dengan DDST (Soetjiningsih, 2013).

Perkembangan anak pada masa prasekolah dipengaruhi oeh faktor hereditas dan lingkungan . faktor lingkungan seperti keluarga, kelompok, sekolah dan media masa. Lingkung keluarga dipandang sebagai faktor penentu bagi perkembangan anak, dimana faktor penentu utama di keluarga adalah orang tua. Peran orang tua terutama ibu sangat penting bagi perkembangan anak karena orang tua dapat segera mengenali kelainan perkembanganan anak sedini mungkin dan memberikan stimulus yang menyeluruh (S. Yusuf, 2011).

Stimulasi adalah kegiatan merangsan kemampuan dasar anak umur 0-6 tahun agar anak Stimulasi dini merupakan serangkaian kegiatan atau aktivitas yang merangsang pembentukan perkembangan dasar anak untuk memberikan pengalaman (early experience) sehingga tumbuh kembang anak menjadi optimal (Christiari AY. Ramzis, 2013). Stimulasi pada anak dapat dilakukan oleh orang tua, pengasuh, keluarga atau orangorang di sekitar anak. Stimulasi yang diberikan dapat berupa verbal, auditori, visual, taktil dan lain-lain. Stimulasi yang diberikan pada masa usia dini (golden age period) dan sesuai dengan aspek tumbuh kembang yang diperlukan akan memberikan dampak yang optimal terhadap perkembangan anak (Depkes, 2012).

Perkembangan bahasa anak yang optimal tidak lepas dari cara orang tua dalam menstimulus anaknya. Keterlambatan perkembangan bicara dan bahasa pada balita di Indonesia cukup tinggi dari beberapa Negara berkembang lainnya. D ari 24.066 jumlah Jumlah balita di Indonesia $68 \%$ anak mengalami keterlambatan dalam berbicara (Kemenkes, 2015).

Bedasarkan data yang didapat dari dinas kesehatan provinsi Sumatra barat tahun 2015, kota padang berada di peringkat pertama yang balitanya mengalami gangguan tumbuh kembang bicara dan bahasa yaitu 434 orang. Kota Solok masuk 5 besar yang balitanya mengalami gangguan tumbuh kembang bicara dan bahasa. Di kota Solok terdapat 4 Puskesmas, dimana Puskesmas Tanah Garam merupakan Puskesmas rujukan dari 3 puskesmas lainnya di kota Solok. Fasilitas yang dimiliki Puskesmas Tanah Garam sudah lengkap, yaitu memiliki dokter spesialis anak, rawat inap ibu dan anak, fisioterapi, kelas pijat bayi, dan terapi bicara. Berdasarkan data yang didapat dari Puskesmas Tanah Garam Kota Solok sebanyak 86 orang anak mengalami ganggungan bicara di wilayah kerja Puskesmas Tanah Garam pada tahun 2017.

Berdasarkan penelitian yang dilakukan Suryani (2013) tentang pengetahuan stimulus orang tua dengan perkembangan bahasa anak 1-3 tahun di kelurahan Pringapus, kecamatan Pringapus, Kabupaten semarang. kepada 62 responden menunjukkan bahwa 38 balita $(61,3 \%)$ memiliki stimulasi baik dan 13 balita 
$(21,0 \%)$ memiliki stimulasi kurang. Didapatkan hasil penelitian kemampuan bicara anak umur 1-3 tahun 48 balita $(77,4 \%)$ normal dan 14 balita $(22,6 \%)$ suspek. Dengan nilai $\mathrm{p}=0,002$ sehingga Ho ditolak (Suryani, 2013).

Studi pendahuluan yang dilakukan oleh peneliti di Wilayah Kerja Puskesmas tanah garam yakni di kelurahan tanah garam pada 10 orang tua, diperoleh data bahwa 4 diantaranya tidak pernah membacakan buku cerita kepada anak berusia Batita. Selanjutnya 3 diantara orang tua tersebut mengatakan jarang sekali mendendangkan lagu-lagu kepada anak usia 12 tahun. Sedangkan 3 diantara orang tua tersebut mengatakan mereka sering bercerita dengan anaknya mulai anak berusia 2-3 tahun. Sedangkan studi pendahuluan yang dilakukan pada 10 orang anak usia Batita didapatkan 2 dari 3 orang anak usia 1 tahun belum mampu menirukan 3 suku kata, 2 dari 4 anak usia 2,53 tahun ucapannya tidak dapat dimengerti.

Tujuan penelitian ini adalah untuk mengetahui Hubungan Stimulasi Orang Tua Terhadap Perkembangan Bicara dan bahasa Anak Usia Batita Di Wilayah Kerja Puskesmas Tanah Garam Kota Solok Tahun 2018.

\section{METODE PENELITIAN}

Jenis penelitian ini adalah penelitian analitik dengan pendekatan cross sectional, Variabel bebas dari penelitian ini adalah stimulasi orang tua, sedangkan variable terikat dari penelitian ini adalah perkembangan bicara dan bahasa anak Batita di wilayah Kerja Puskesmas Tanah Garam Kota Solok Tahun 2018. Penelitian ini dilaksanakan pada bulan Juni tahun 2018 hingga Agustus tahun 2018 dan tempat pelaksanaan penelitian ini adalah di ruangan anak Puskesmas tanah Garam Kota Solok. Populasi dari penelitian ini adalah anak usia 1-3 tahun yang diambil diwilayah Kerja Puskesmas Tanah Garam Kota Solok yang berjumlah 109 orang responden. Sampel pada penelitian ini berjumlah 86 ibu dan anak usia 1-3 tahun. Pemilihan sampel penelitian ini Dilakukan
Dengan Menggunakan Teknik consecutive sampling. Data dikumpulkan mengunakan kuesioner dengan format the capute scales scoring sheet. Data dianalisa mengunakan analisa univariat dan bivariat dengan uji statistik Chi-Square yang disajikan dalam bentuk tabel.

\section{HASIL DAN PEMBAHASAN Analisa Univariat}

Analisa univariat digunakan untuk melihat distribusi frekuensi dari variabel dependen dan independen

\section{Stimulasi Orang Tua}

Tabel 1 Distribusi Frekuensi Stimulasi Orang Tua di Wilayah Kerja Puskesmas Tanah Garam Solok Tahun 2018

\begin{tabular}{|c|l|c|c|}
\hline No & Stimulasi & F & $\%$ \\
\hline 1. & Kurang & 50 & 58 \\
& Optimal & & \\
\hline 2. & Optimal & 36 & 42 \\
\hline & Total & 86 & 100 \\
\hline
\end{tabular}

Berdasarkan tabel 1 dapat diketahui bahwa lebih dari separoh responden (58\%) di Wilayah Kerja Puskesmas Tanah Garam Kota Solok kurang optimal menlakukan stimulasi perkembangan terhadap anak batita.

\section{Perkembangan Bicara dan Bahasa Batita}

Tabel 2. Distribusi Frekuensi

Perkembangan Bicara dan Bahasa Anak

\begin{tabular}{|c|c|c|c|}
\hline No & $\begin{array}{c}\text { Perkembangan } \\
\text { Bicara }\end{array}$ & F & \% \\
\hline 1. & Suspek & 31 & 42 \\
\hline 2. & Normal & 55 & 58 \\
\hline & Total & 86 & 100 \\
\hline
\end{tabular}

Pada tabel 2 di atas dapat diketahui bahwa hampir separoh responden (42\%) di wilayah kerja Puskesmas Tanah Garam Kota Solok anak batita mengalami suspek dalam perkembangan bicara dan bahasa 


\section{Analisa Bivariat}

Tabel 3.Hubungan Antara Stimulasi Orang Tua Dengan Perkembangan Bicara Dan Bahasa Usia Batita

\begin{tabular}{|c|c|c|c|c|c|c|c|}
\hline \multirow{3}{*}{$\underset{\mathbf{s i}}{\text { Stimula }}$} & \multicolumn{4}{|c|}{$\begin{array}{c}\text { Perkembangan } \\
\text { Bicara dan Bahasa } \\
\text { anak }\end{array}$} & \multirow{2}{*}{\multicolumn{2}{|c|}{ Jumlah }} & \multirow{3}{*}{$\underset{\text { value }}{\mathbf{P}}$} \\
\hline & \multicolumn{2}{|c|}{ Suspek } & \multicolumn{2}{|c|}{ Normal } & & & \\
\hline & $\mathbf{n}$ & $\%$ & $\mathbf{n}$ & $\%$ & $\mathbf{n}$ & $\%$ & \\
\hline $\begin{array}{c}\text { Kurang } \\
\text { Optimal }\end{array}$ & 26 & 52 & 24 & 48 & 50 & $\begin{array}{c}10 \\
0\end{array}$ & \\
\hline Optimal & 5 & 14 & 31 & 86 & 36 & $\begin{array}{c}10 \\
0\end{array}$ & 0.001 \\
\hline Jumlah & 55 & 64 & 31 & 36 & 86 & $\begin{array}{c}10 \\
0\end{array}$ & \\
\hline
\end{tabular}

Dari tabel 3 menunjukan bahwa ibu yang kurang optimal menstimulasi perkembangan bicara anak dan mengalami suspek didapatkan sebanyak 26 orang (52\%) sedangkan balita yang mendapatkan stimulasi yang optimal dari orang tua nya yang mengalami suspek 5 orang $(14 \%)$. Hasil uji statistic didapatkan nilai $\mathrm{p}=0.001(\mathrm{p}<0,05)$ yang artinya terdapat hubungan antara stimulasi dengan perkembnagan bicara dan bahasa anak batita.

Hasil penelitian yang dilakukan kepada 86 responden menunjukan bahwa ibu yang menstimulasi anaknya dengan optimal dan perkembangan bicara anak yang normal didapatkan sebanyak 31 orang (86\%) sedangkan perkembangan bicara dan bahasa anak yang mengalami suspek 5 orang (14\%). Dibandingkan dengan ibu yang kurang optimal dalam menstimulasi anak dengan perkembangan bicara dan bahasa anak yang normal adalah sebanayak 24 orang (48\%) sedangkan ibu yang memiliki anak dengan suspek adalah sebanyak 26 orang (52\%). Hasil uji chi square didapatkan nilai $\mathrm{p}$ value adalah 0.001 yang artinya terdapat hubungan yang signifikan antara stimulasi dengan perkembnagan bicara dan bahasa anak batita.

Tindakan memberikan stimulasi pada anak adalah untuk membantu anak mencapai tingkat perkembangan optimal atau sesuai dengan apa yang diharapkan. Stimulasi dilakukan oleh orangtua atau keluarga setiap ada kesempatan atau sehari-hari. Stimulasi disesuaikan dengan usia anak tersebut dengan tidak mengabaikan prinsip-prinsip stimulasi. Artinya stimulasi diberikan dengan tingkat atau fase perkembangan psikologis anak untuk menghindari terjadinya kerusakan berbahasanya pada fase berikutnya. Mengingat bahwa perkembangan bahasa pada usia pra sekolah adalah hal yang sangat penting yang akan menentukan perkembangan bahasanya kelak (tahap pro konseptual). Respon perkembangan bahasa ini adalah periode seorang anak mengerti akan banyak hal, dengan kata lain merupakan tahap awal (golden period) yang sangat menentukan dan berpengaruh yang sangat menentukan dan berpengaruh dalam perkembangan bahasa anak pada tahap berikutnya.Yang perlu ditekankan bahwa perkembangan bahasa adalah domain terhadap perkembangan anak yang lain, maka dari itu stimulasi yang baik, terarah dan benar adalah hal yang penting diketahui oleh semua orangtua dengan anak usia pra sekolah.Disini jelas dibutuhkan suatu pemahaman dan kreatifitas dalam memberikan stimulasi. Menurut Goldner bahwa kreativitas merupakan kegiatan otak yang teratur, komprehensif dan imajinatif menuju suatu hasil yang optimal. Jadi inovatif lebih ditekankan dalam memberikan stimulasi bahasadaripada unsur reproduktifnya.

Hasil penelitian Yusuf, (2017) rendahnya tingkat pengetahuan ibu tentang tumbuh dan kembang pada anak balita usia 3-5 tahun di wilayah kerja puskesmas ulak karang kota padang dikarenakan ibu tidak tahu berapa kali DDTK dilakukan pada balita dilakukan dalam setahun.Lebih terbukti dari hasil beberapa jawaban yang salah yang diberikan ibu $(75 \%)$ jawaban salah pada pertanyaan bertambahnya berat badan anak merupakan suatu proses, (75\%) jawaban salah pada pertanyaan tahap pertama Deteksi Dini Tumbuh Kembang secara periodik dilakukan pada anak balita yang ber (Yusuf, R N, 2017)

Hasil penelitian ini didukung dengan hasil penelitian yang dilakukan oleh Yektiningsih (2010) yang menemukan hasil bahwa ada hubungan yang erat antara pemberian stimulasi oleh orang tua dengan perkembangan bahasa pada anak anak usia pra sekolah (3-5 tahun) di Taman Kanak-Kanak Alfath Pare. Penelitian lain yang dilakukan oleh Widiantoro, E \& Prawesti (2013) juga 
menemukan hasil bahwa ada hubungan pemberian stimulasi oleh orang tua dengan perkembangan anak usia 3-5 tahun. Mereka juga menyimpulkan bahwa orang tua yang memberikan stimulus dapat berdampak baik pada tumbuh kembang anak yaitu sesuai dengan tahap perkembangan yang normal

Dari hasil penelitian yang dilakukan oleh Putra, AY. Yudiemawati, A. Maemunah (2018) Pengaruh Pemberian Stimulasi Oleh Orang Tua Terhadap Perkembangan Bahasa Pada Anak Usia Toddler Di Paud Asparaga Malang tahun 2018 didapatkan hasil bahwa terdapat hubungan yang signifikan antra stimulasi dengan perkembangan bicara anak dan bahasa anak dengan nilai p value (0.005). Penelitian ini juga selaras dengan penelitian yang dilakukan oleh Habibi Tetang hubung stimulasi dengan perkembangan anak di Dusun Petet Desa Tuntang Kecamatan Tuntang Kabupaten Semarang Tahun 2009 bahwa terdapat hubungan signifikan antara stimulasi dengan perkembangan bicara anak dengan nilai $\mathrm{p}$ value $(0.023)$.

Menurut asumsi peneliti hal ini disebutkan bahwa stimulasi dan perkembangan bicara dan bahasa anak sangat berpengaruh sekali hal ini juga dipengaruhi oleh beberapa factor diantaranya kebiasaan orang tua yang sering memegang $\mathrm{Hp}$, pendidikan orang tua rata-rata hanya sampai SMU jadi orang tua kurang tahu cara dan manfaat dari stimulasi bicara untuk anak balita dan kebiasaan orang tua yang suka memberikan gadget kepada anakya. Orang tua yang menganggap memberikan gadget merupakan salah satu cara yang baik dan mudah dalam mengawasianak ketikadirumah.Balita yang menggunakan gadget dapat mempengaruhi kontak social dan komunikasi. Ketika menggunakan gadget ,balita akan focus dengan gadget nya dan tidak peduli dengan lingkungan sekitar. Selain itu, gadget dapat menyebabkan kecanduan pada balita sehingga balita lebih senang bermain gadget daripada bermain bersama temantemannya (bersosialisasi) dan jarang berbicara dengan orang sekitarnya. Hal ini menyebabkan balita kurang atau tidak mendapatkan stimulasi dan dapat mempengaruhi perkembangan bicara dan bahasa.

\section{SIMPULAN}

Dapat disimpulkan bahwa terdapat hubungan antara stimulasi dengan perkembangan bicara dan bahasa anak batita. Diharapkan Tenaga kesehatan mempunyai peran penting untuk memberikan penyuluhan kepada orang tua tentang pentingnya stimulasi untuk perkembangan bicara dan bahasa anak balita secara berkesinambungan Hasil penelitian ini dapat dijadikan sebagai referensi yang relevan dan membantu penelitian sejenis terkait dengan kejadian keterlambatan perkembangan bicara dan bahasa pada balita. Peneliti selanjutnya diharapkan dapat meneliti lebih mendalam mengenai keterlambatan perkembangan pada balita dengan menggunakan sampel yang lebih banyak.

\section{UCAPAN TERIMA KASIH}

Penulis mengucapkan terima kasih kepada rekan serta pihak-pihak terkait atas semua kontribusi dan membantu menyelesaikan penelitian ini, serta kepada Yayasan Pengembangan Sumber Daya Manusia (YPSDM) Sumatera Barat atas dukungan, sehingga penelitian ini dapat diselesaikan sesuai yang dijadwalkan.

\section{DAFTAR PUSTAKA}

Christiari AY. Ramzis, I. F. (2013). Hubungan Pengetahuan Ibu Tentang Stimulasi Dini Dengan Perkembangan Motorik Pada Anak Usia 6-24 Bulan Di Kecamatan Mayang Kabupaten Jember. Pustaka Kesehatan.

Depkes, R. (2012). Pedoman Pelaksanaan Stimulasi. Deteksi Dan Intervensi Dini Tumbuh Kembang Anak Ditingkat Pelayanan Kesehatan Dasar. Jakarta: Depkes RI.

Hartanto. Selina, Zubrial \& Fitra, S. (2011). Pengaruh Perkembangan Bahasa Terhadap Perkembangan Kongitifanak Usia 1-3 Tahun. Sari Pedriatri.

Kemenkes, R. (2015). Data Dan Informasi Tahun 2014. (ProfiI Kesehatan Indonesia). Jakarta: Kemenkes RI.

Putra, AY. Yudiemawati, A. Maemunah, N. 
(Jurnal Ilmu Kesehatan)

(2018). Pengaruh Pemberian Simulasi Oleh Orang Tua Terhadap Perkembangan Bahasa Pada Anak Usia Toddler di PAUD Asparaga Malang. Nursing News, 3(1).

Soetjiningsih. (2013). Tumbuh Kembang Anak (2nd ed.). Jakarta: Salemba Medika.

Suryani. (2013). Pengetahuan Stimulasi Orang Tua Dengan Perkemnang Anak 1-3 Tahun Dikelurahan Pringapus kecamatan Pringapus Kabupaten Semarang.

Widiantoro, E \& Prawesti, D. (n.d.). Pemberian Stimulasi Terhadap
Perkembangan Anak Usia 3-5 Tahun. STIKES, 6(1).

Yektiningsih. (2010). Hubungan Pemberian Simulasi Oleh Orang Tua Dengan Perkembangan Bahasa Anak Usia Pra Sekolah 3-5 tahun di Taman Kanakkanak Al Fath Pare. AKP, 2.

Yusuf, R. N. (2017). Analisis Tingkat Pengetahuan Ibu Tentang Tumbuh Dan Kembang Pada Anak Balita Usia 3-5 tahun. Medika Saintika, 8(2).

Yusuf, S. (2011). Perkembanga Anak Dan Remaja. Bandung: Pr Raja Frafindo Persada. 